C. A. WANG, Z. K. ZHANG, T. YUE, Y. L. SUN, L. WANG, W. D. WANG, Y. ZHANG, C. LIU, W. WANG* (LANZHOU UNIVERSITY, P. R. OF CHINA)

'Bottom-Up' Embedding of the Jørgensen-Hayashi Catalyst into a Chiral Porous Polymer for Highly Efficient Heterogeneous Asymmetric Organocatalysis

Chem. Eur. J. 2012, 18, 6718-6723.

\section{Asymmetric Michael Addition of Aldehydes to Nitroalkenes Using JH-CPP}

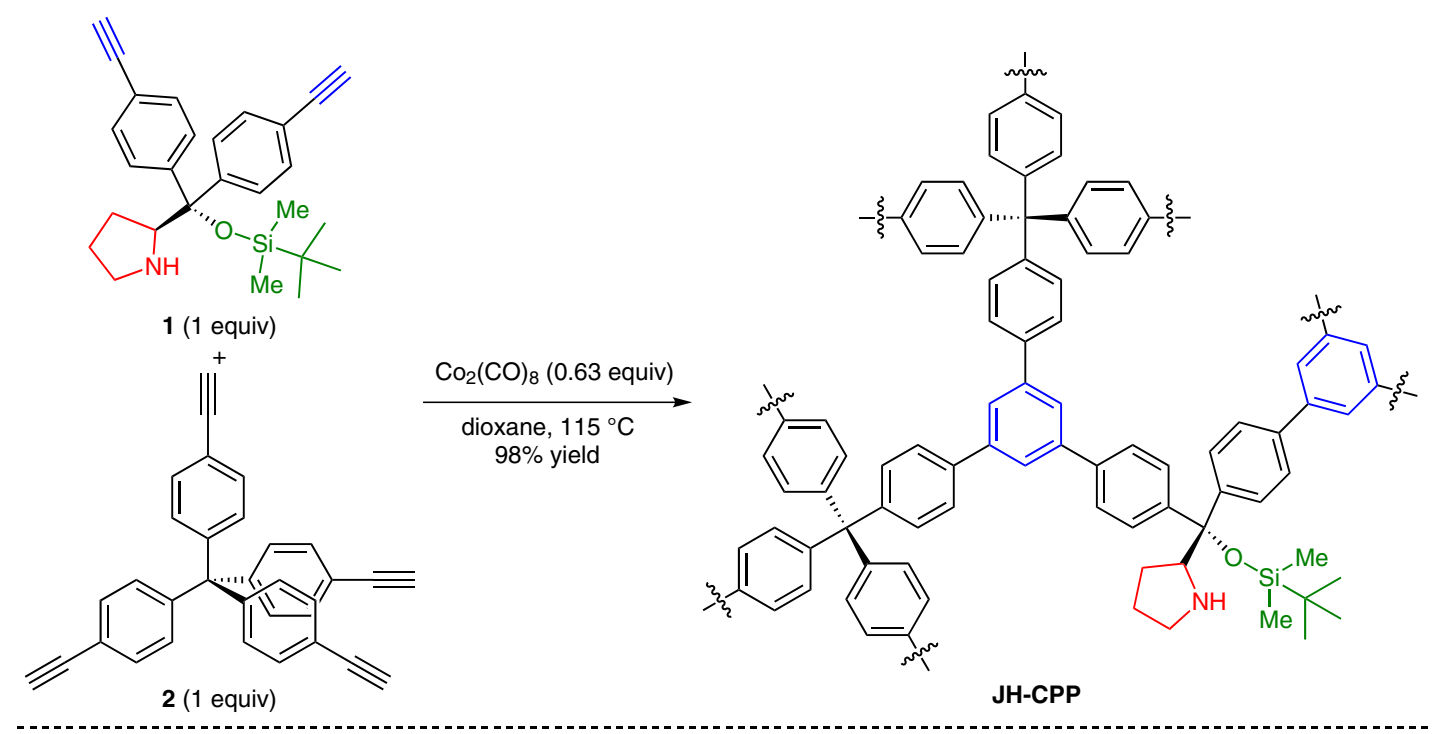

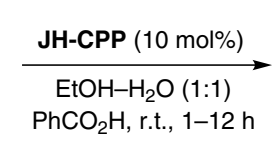

$\overbrace{\mathrm{R}_{5}}^{\mathrm{Ar}} \mathrm{NO}_{2}$

10 examples

$67-99 \%$ yield, dr from $74: 26$ to $97: 3$

93-99\% ee

Selected examples:<smiles>CC(C=O)C(C[N+](=O)[O-])c1ccccc1</smiles>

5 a

$99 \%$ yield, $d r=92: 8$ $98 \%$ ee<smiles>CC(C=O)C(C[N+](=O)[O-])c1ccc(Cl)cc1</smiles>

$5 b$

$96 \%$ yield, $\mathrm{dr}=92: 8$ $99 \%$ ee<smiles>COc1ccc(C(C[N+](=O)[O-])C(C)C=O)cc1</smiles>

$5 c$ $88 \%$ yield, $d r=91: 9$ $98 \%$ ee
Gategory

Polymer-Supported

Synthesis

Key words

Jørgensen-Hayashi catalyst

chiral porous polymers

Michael addition

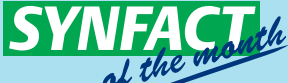

Significance: A chiral porous polymer containing the Jørgensen-Hayashi catalyst (JH-CPP) was prepared by the $\mathrm{CO}_{2}(\mathrm{CO})_{8}$-mediated trimerization of the ethynyl-modified Jørgensen-Hayashi catalyst $\mathbf{1}$ with tetra(4-ethynylphenyl)methane (2) in 98\% yield. JH-CPP catalyzed the asymmetric Michael addition of aldehydes $\mathbf{4}$ to nitroalkenes $\mathbf{3}$ to give the corresponding adducts 5 in $67-99 \%$ yield with high stereoselectivity (10 examples).
Comment: For the formation of $\mathbf{5 b}$, JH-CPP was recovered by centrifugation and reused four times without loss of stereoselectivity, while the yield of $\mathbf{5 b}$ decreased from the third reuse $\left(1^{\text {st }}\right.$ reuse: 94\% yield, $98 \%$ ee, $d r=92: 8 ; 3^{\text {rd }}$ reuse: $51 \%$ yield, $97 \%$ ee, $d r=91: 9 ; 4^{\text {th }}$ reuse: $39 \%$ yield, 97\% ee, $\mathrm{dr}=88: 12)$. JH-CPP was characterized by $\mathrm{N}_{2}$ adsorption, TGA, XRD, SEM, and ${ }^{13} \mathrm{C} \mathrm{CP} /$ MAS NMR spectroscopy.

SYNFACTS Contributors: Yasuhiro Uozumi, Hiroaki Tsuji

Synfacts 2012, 8(8), 0913 Published online: 19.07.2012

Dol: 10.1055/s-0032-1316675; Reg-No.: Y06712SF 